
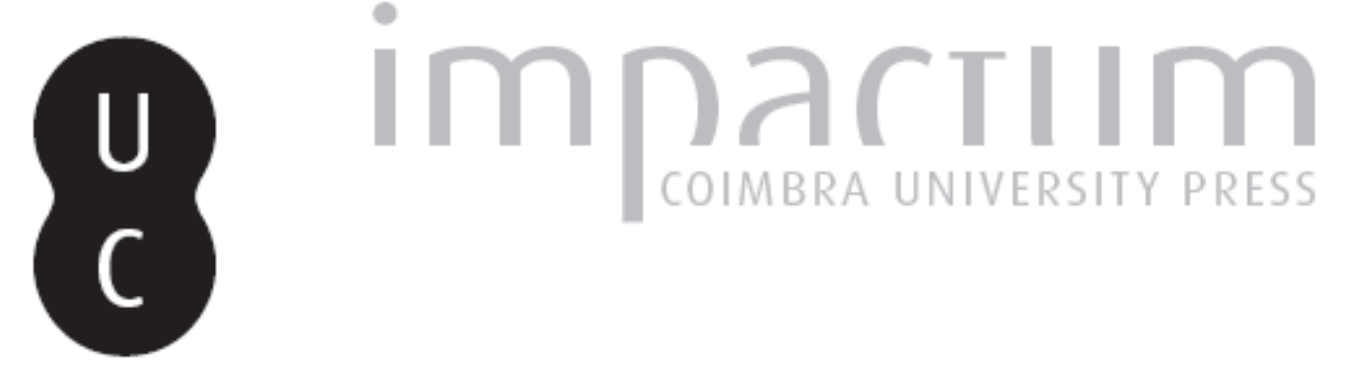

\title{
Educação: necessidade e mudança: no centenário da Faculdade de Letras, a pedagogia como uma constante
}

Autor(es): Boavida, João

Publicado por: Faculdade de Letras da Universidade de Coimbra

URL persistente:

URI:http://hdl.handle.net/10316.2/32415

DOI:

DOI:http://dx.doi.org/10.14195/0870-4112_9_6

Accessed : $\quad$ 26-Apr-2023 09:49:31

A navegação consulta e descarregamento dos títulos inseridos nas Bibliotecas Digitais UC Digitalis, UC Pombalina e UC Impactum, pressupõem a aceitação plena e sem reservas dos Termos e Condições de Uso destas Bibliotecas Digitais, disponíveis em https://digitalis.uc.pt/pt-pt/termos.

Conforme exposto nos referidos Termos e Condições de Uso, o descarregamento de títulos de acesso restrito requer uma licença válida de autorização devendo o utilizador aceder ao(s) documento(s) a partir de um endereço de IP da instituição detentora da supramencionada licença.

Ao utilizador é apenas permitido o descarregamento para uso pessoal, pelo que o emprego do(s) título(s) descarregado(s) para outro fim, designadamente comercial, carece de autorização do respetivo autor ou editor da obra.

Na medida em que todas as obras da UC Digitalis se encontram protegidas pelo Código do Direito de Autor e Direitos Conexos e demais legislação aplicável, toda a cópia, parcial ou total, deste documento, nos casos em que é legalmente admitida, deverá conter ou fazer-se acompanhar por este aviso.

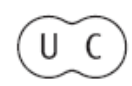



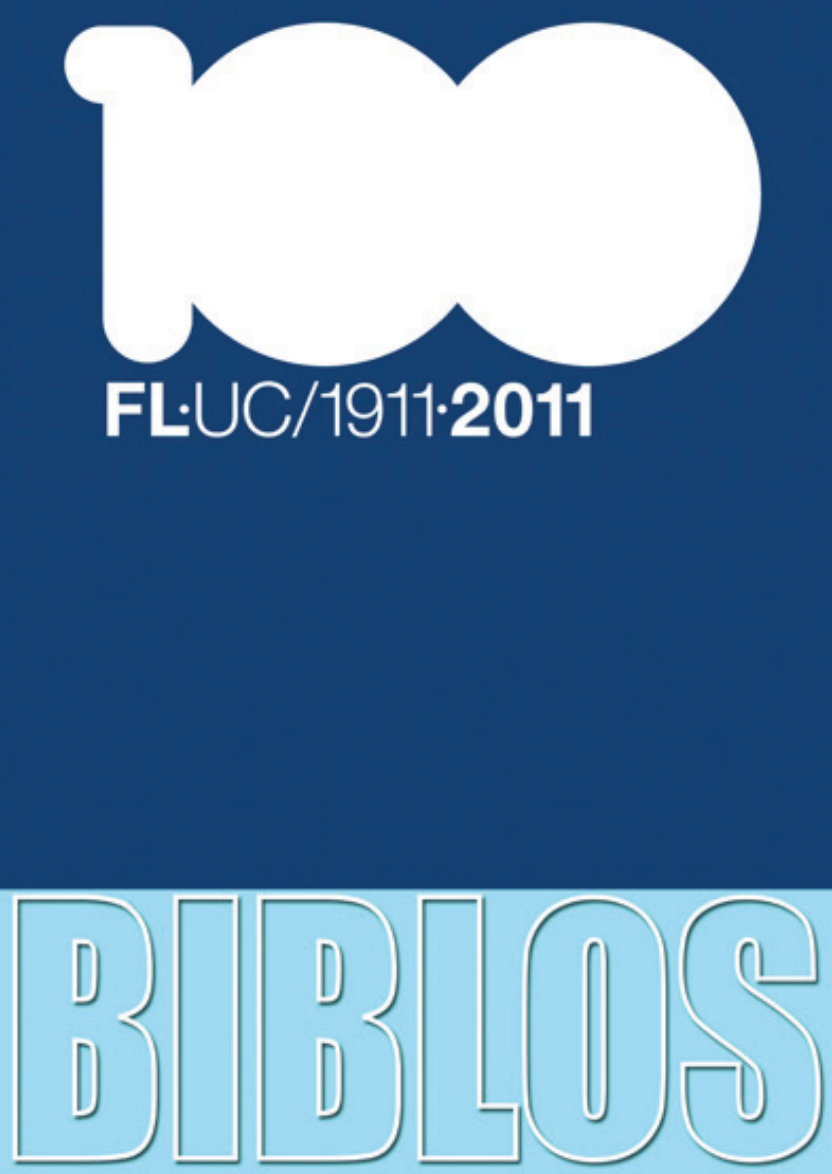

REVISTA DA FACULDADE DE LETRAS UNIVERSIDADE DE COIMBRA 
Biblos, n. s. IX (2011) 195-216

JoÃo BoAVIDA

Faculdade de Psicologia e de Ciências da Educação

Universidade de Coimbra

\title{
EDUCAÇÃO: NECESSIDADE E MUDANÇA
}

No centenário da Faculdade de Letras,

a pedagogia como uma constante

\section{Resumo}

Partindo da ideia de que a educação é uma necessidade em evolução, a situação da crise atualé um conjunto de problemas inerenteàs novas conjunturas socioculturais e económicas. Os meios e os modos para as ultrapassar são já nossos conhecidos e têm sido investigados pelas universidades, mas os agentes educativos terão hoje que os assumir e reativar. Nos últimos cem anos, desde a criação da Faculdade de Letras, que substituiu a Faculdade de Teologia, deram-se alguns passos significativos, como, por exemplo, a criação da Escola Normal Superior, adstrita à Universidade, o $1^{\circ}$ Laboratório de Psicologia Experimental em Portugal, a Revista Portuguesa de Pedagogia, etc.

Palavras-Chave: Educação, Necessidade, Mudança, Problema, Superação.

\begin{abstract}
Starting from the idea that education is an evolving need, the current situation of crisis presents a set of problems inherent to the new socio-cultural and economic conjunctures. The means and ways to overcome these problems are already known and have been studied by Universities, but the educational providers must now take over and revive them. Since the Faculty of Arts and Humanities substituted the Faculty of Theology one hundred years ago, some significant steps have been taken in that direction, such as the foundation of the Teachers' College (Escola Normal Superior), the first Laboratory of Experimental Psychology in Portugal, and the creation of the journal Revista Portuguesa de Pedagogia (Portuguese Pedagogy Review), among others.
\end{abstract}

Keywords: Education, Need, Change, Problem, Overcome. 


\section{Introdução}

A Universidade encontra-se em profundo processo de reformulação. O qual é social - pela atual demanda massiva do ensino superior, é económico - pela crescente importância da investigação científica e sua aplicação à técnica e ao tecido económico e social, e é também cultural - pelas múltiplas interações cognitivas, psicológicas e estéticas. Por todas estas razões é, obviamente, um problema político. Mas há uma questão central que resulta da dificuldade em articular a massificação da ciência e da cultura com a necessidade de elevar os padrões de investigação. E, simultaneamente, manter níveis de exigência no ensino, com agora maiores dificuldades na aprendizagem, segundo parece, e necessitando de transformar a avaliação num processo funcional e mais justo, sem deixar de ser exigente.

Como conciliar todas estas dinâmicas conflituantes? E em que medida a necessidade de superar estes problemas vem revalorizar contributos que foram frequentemente considerados laterais ou sentidos como dispensáveis no concerto das ciências e da investigação? Eis um tema interessante no ano da comemoração do centenário da fundação da Faculdade de Letras da Universidade de Coimbra. Em que medida as novas condições por que passa a Universidade em geral nos obrigam a ir ao encontro de contributos significativos, na área das ciências humanas e sociais, desenvolvidos na Faculdade de Letras, por alguns dos seus investigadores, e divulgados pelas suas publicações? Não estará o tempo e a circunstância a revalorizá-los?

A perspetiva clássica de ensinar, aprender e avaliar não parece ter condições para responder a esta situação nova. Torna-se pois indispensável ir à procura dos ensinamentos dos grandes pedagogos, dos clássicos e, sobretudo, dos modernos, e introduzi-los numa dinâmica de transformação profunda, porque é na revalorização desta componente e na sua integração dinâmica no processo, que estará a superação dos problemas atuais.

Parece pois necessário revalorizar a componente pedagógica em geral e a psicopedagógica em particular. $\mathrm{O}$ que quer dizer introduzir a investigação pedagógica na problemática e na investigação científica universitárias. Mas isto irá implicar alterações profundas, tanto no ensino como na aprendizagem, se os quisermos potenciar e requalificar. Porque não se trata de uma pedagogia de facilitação mas de novos modos de fazer e de interagir, e de procurar uma intrínseca funcionalidade, 
um processo em que investigação, ensino, aprendizagem e avaliação se terão que reposicionar e funcionalizar, potenciando-se simultânea e mutuamente.

Ao contrário do que possa parecer, a Universidade não precisa de ir buscar a pedagogia e a psicologia a qualquer mercado de última hora e fora dos seus muros. A Universidade Portuguesa, através de alguns dos seus melhores investigadores, desde cedo, e assim que a investigação psicopedagógica foi produzindo informação, procurou acompanhá-la, e aplicá-la, tentando em muitos sectores modernizar o ensino e encontrar soluções para os problemas com que a sociedade se defrontava. Nesta hora de problemáticas cruciais, uma certa memória institucional pode ser bem mais que uma evocação comemorativa. Pode ser, de facto, o reencontro com uma ideia poderosa, o descobrir de uma estratégia que, sendo até há pouco aparentemente desnecessária, e por isso de algum modo esquecida, se revela, hoje, face às novas situações, o caminho mais adequado.

1. O tema deste trabalho, Educação - necessidade e mudança é assim, mais do que uma proposta de reflexão sobre um tema - a educação - que dir-se-á gasto, porque parece ter-se dito e discutido tudo, um modesto contributo para a homenagem a uma Faculdade a que muito devo, mas também uma achega para a problemática que atravessa hoje a Universidade, a partir de uma ideia de funcionalidade pedagógica, de que se fala há muito mas que pouco se pratica.

Permita-se-me, a propósito, uma evocação agradecida. Foi na Faculdade de Letras da Universidade de Coimbra que comecei a minha formação universitária, no longínquo ano de 1963. E a experiência intelectual e humana desses anos foi tão rica, que a estrutura mental que então pude construir foi a base do meu percurso pessoal e profissional. Tive a sorte de ter alguns grandes mestres, exemplos de competência, de erudição e de humanidade. E a agitação intelectual, a problematização e as vivências culturais foram uma experiência que me marcou para sempre. É pois à memória desses queridos mestres que dedico este modesto trabalho.

2. Pretendo pensar a educação sob a ótica da sua necessidade, que gera a mudança, ou seja, a educação é uma necessidade em constante mudança, embora possa parecer o contrário. E pretendo encarar a 
questão sob esta ótica porque, embora sobre a educação já tudo se tenha dito, continuamos mergulhados numa turbulência em muitos aspetos inédita. O que parece dar razão aos que pensam que nunca a crise foi tão aguda, o que confirma a necessidade de continuar a analisar e a tentar compreender o fenómeno educativo. É inevitável; a educação é demasiado importante, e confrontados com problemas novos teremos que encontrar saídas adequadas, por mais que a situação seja complexa e dilemática.

É certo que temos tendência para pedir hoje à educação mais do que ela pode dar. Sobretudo em tempos de crise. Quando mais se sente o incómodo da mudança, e quando mais se torna premente a necessidade dela, mais estão em crise os meios necessários para o conseguir. Mas há conceitos que parecem "esquecidos" em tempo de estabilidade e que, revisitados em épocas de turbulência, se revelam indispensáveis.

3. Em primeiro lugar, a ideia de crise. Porquê? Quando se fala de educação vem-nos ao espírito a ideia de crise; hoje, como ontem. Como se sabe, é uma ideia recorrente no discurso habitual. Mas o que é que, de facto, significa, nos nossos dias, a expressão "crise educativa"? Em que consiste, tendo em conta que esta ideia andou, desde a Antiguidade, na boca de educadores e de simples cidadãos, e que não podemos deixar de descontar a componente regressiva e saudosista que a idade vai acrescentando em todos nós e nos vai levando a criticar o presente e a valorizar o passado? Para lá do facto de que, em boa medida, a crise educativa será uma regressão psico-afectiva dos mais velhos, o que está, na educação atual, efetivamente em situação crítica? Talvez a ideia, de facto nova, não tanto na teoria mas na prática de muita gente, de que ela se tornou desnecessária, ou quase.

Porém, como esquecer, ou mesmo só desvalorizar, a evidência da sua necessidade? Octavi Fullat (1983), na linha de Dewey, fala da Educação como necessidade vital. E também como função social e como direção, sendo pois, por estas razões, também uma realidade com sentido. Analisando estes conceitos somos confrontados com uma conceção de educação muito mais funda e alargada que a atual educação escolarizada e formal. Esta maior abrangência é indispensável à compreensão do problema, porque a educação, sendo uma necessidade vital, é, e sempre foi, uma condição da sobrevivência tanto dos indivíduos como da espécie. 
De facto, os seres vivos conservam-se e renovam-se por um processo interativo em que as capacidades novas surgem das anteriores à medida que vamos sendo capazes de ultrapassar dificuldades que até aí não conseguíamos. E essa criação por necessidade transforma-se em novas capacidades que, reformuladas, se conservam e transmitem pela sua função vital para a sobrevivência, ao mesmo tempo que constituem um fator condicionador e agregador dos elementos do grupo. E isto porque, é óbvio, sem o grupo este processo não funciona, uma vez que é o grupo que possibilita a sobrevivência e o desenvolvimento individual.

Por isso, segundo Dewey, a educação é condição de dinâmica e de interação social, e estas, a base da coesão, da vitalidade e da qualidade da sociedade. E assim, a educação, por este processo articulado de criação, conservação, transmissão e renovação, garante a vida do grupo e é dele consequência e causa. Por outro lado, mesmo que, durante milénios, não se tenha tido consciência disso, este processo revela o sentido que lhe é dado pela evolução dos saberes, das técnicas e dos modos de resolver os problemas, em contextos sempre transitórios. $\mathrm{O}$ aperfeiçoamento nos modos, nas técnicas e nos conhecimentos disponíveis define uma tendência, a qual é fator e agente da evolução social. Este esquema continua a vigorar hoje, como sempre, embora com níveis de transferência e de complexidade muito maiores. Mas isso não retirou à educação a necessidade, nem a dimensão vital, antes pelo contrário.

Os conceitos de necessidade e de função vital permitem assim compreender o de mudança, e os três dão razão de ser à ideia de que a educação tem sempre um sentido, por muito errática que seja a progressão. Ora, é sobretudo o conceito de mudança que cria a ideia de crise e, deste modo, a torna uma constante, pela constante mudança que se verifica em tudo. Porque, nestas condições, a educação é mudança e transformação; de comportamentos, de atitudes, de modos de ser e fazer, de aprendizagens, de experiências, etc. Mas também mudança nos métodos e nos processos, que se vão aperfeiçoando e reformulando pela experiência, que os seleciona de acordo com os efeitos.

4. Mas a mudança vai acontecendo também nos princípios, nas finalidades e em muito do que, segundo o ponto de vista corrente, é suposto não mudar, ou que entendemos não dever mudar. Mas que, apesar disso, vai mudando, sempre, embora a velocidades diferentes, conforme as 
épocas, os lugares e as pessoas. Ora, um dos problemas mais complexos e ambivalentes da educação está nesta dupla natureza de mudança e de estabilidade; isto é, de necessidade de solução para novos problemas, mas a partir de bases assentes em esquemas regressivos. Porque, segundo um ponto de vista corrente, de natureza predominantemente psicoafetiva, são as práticas que se afastam dos princípios, que os não respeitam, criando crise e degradação. Mas, segundo outra perspetiva, não só as práticas e os hábitos se degradam, afastando-se dos princípios, mas também estes empalidecem e entram em colapso. E esta perspetiva, mais racionalista, introduz, ou parece introduzir, uma outra dimensão mais profunda e estrutural no conceito de crise educativa.

E assim é, porque para lá de um ou outro princípio de validade universal, sempre problemático, o que acontece é que nós vamos postulando "princípios" que, de algum modo, também eles estão sujeitos à mudança. $\mathrm{O}$ que põe em causa a ideia de princípio, a partir da convicção de que o princípio é inamovível e eterno, e gerando, nas perspetivas individuais e respetivas experiências, a ideia de corte, de ferida irremediável. Mas, como o princípio continua a ser necessário, e todo o ato coerente o postula, há aqui um conflito entre o sentimento individual de trauma, porque se rompeu o que não era possível romper-se, e a sociedade que, apesar de tudo vai postulando novos princípios, ou variações dos mesmos princípios, ou até oscilações dialéticas deles. Mas estas intermitências em volta de conceitos (que evoluem o mínimo, para se manterem, e mantêm-se porque não permitem grandes variações) só se tornam evidentes a partir de uma perspectiva temporal que ultrapassa os sentimentos individuais e dos pequenos grupos, os quais dispõem de um âmbito temporal muito restrito. $\mathrm{O}$ que acrescenta a ideia de crise.

E, portanto, o conceito de crise é simultaneamente endógeno e exógeno à educação. Endógeno, na medida em que a prática educativa e o seu pensamento estão inseridos no social e nas suas mudanças; mas exógeno à ideia que postulamos de educação, a partir da necessidade do princípio e do seu valor universal. E também à ideia de organização do mundo que, em cada um de nós, na infância, toda a boa educação deve ter gerado. Ora, esta dupla perspetiva crísica parece pôr em causa a própria educação. Porque pressupõe uma estabilidade de referências, e só aceita mudanças relativas aos indivíduos e suas variáveis, e não em ordem aos padrões, que, segundo o sentimento comum, não devem 
mudar, mas que todavia vão mudando. $\mathrm{E}$ assim se cria um conflito constante entre os indivíduos e a evolução, estrutural e funcional, a que a educação e os contextos socioculturais estão sujeitos.

5. O quadro que apresentei, que se pode considerar um exercício de reflexão, esquemático e abstrato, pretende dar algumas chaves para o entendimento de certas transformações no plano educativo. Muitos dos problemas com que nos defrontamos poderão até nem ser verdadeiros problemas, mas antes soluções imperfeitas, ou transitórias, restos de situações problemáticas anteriores, e para as quais ainda não se encontrou um equilíbrio entre o que se necessita e a capacidade de responder adequadamente a essas necessidades. Nunca há soluções definitivas, como se sabe. E como não era definitiva a situação de onde se partiu, que, contudo, nos serviu de referência, somos muitas vezes levados a considerá-la como modelo estável quando não era, de facto, mais do que uma situação provisória e com as soluções que ao tempo se achavam as melhores. Deste modo fomos enquistando problemas e soluções. Que não seriam problemas nem soluções, mas fases, sempre transitórias, de um processo contínuo e mais vasto cuja interpretação, contudo, nem sempre fazemos corretamente.

Apresentarei, como tentativa de exemplificação, dois casos próximos: um, já ultrapassado, para o melhor e o pior - o que significa não estar resolvido, mas que deverá interpretar-se como uma sequência de aporias e de superações; o outro, constituído por um conjunto de problemas que, dir-se-ia, alguém, por maldade, andou a criar para nós, mas que se deverá integrar no mesmo esquema interpretativo. Refiro-me à transformação a que foram sujeitos os ensinos básico e secundário, durante o século $\mathrm{XX}$, e às atuais alterações no ensino superior, referidas genericamente por "processo de Bolonha". Como se chegou à presente situação? Como iremos sair dela?

6. Em primeiro lugar, temos de partir do contexto em que se tornou evidente a necessidade de mudança e, em seguida, tentar perceber as tentativas de solução, mesmo quando levantam novos problemas. Poderemos dizer que o século XX protagonizou uma transformação profunda em termos educativos, tanto a nível pedagógico-escolar como social e familiar. Mas também que estas transformações trazem em si algumas das problemáticas mais constantes da educação; e que 
não podemos entendê-las convenientemente se as não inserirmos no processo sociocultural em que se integram.

Desde logo, há que assinalar uma oscilação, dir-se-ia dialética, entre uma pedagogia tendencialmente rígida e formal, assente na transmissão de conhecimentos e na exigência da sua memorização e reprodução, que vigorou durante quase todo o século XIX, e um conjunto de ideias novas preocupadas sobretudo em dinamizar os modos de aprender e em promover o trabalho autónomo dos alunos. E oscilou em dois sentidos: num sentido estrutural e noutro psicoafetivo. Ou seja, em termos de ideias dominantes, de modelos de formação e de conceção geral da escola, e sua função formativa; e no modo como cada agente/participante assimilou, interiorizou e pôs em prática estas ideias e definiu estas metas. Em termos históricos e estruturais, digamos assim, esta mudança de conceitos e de práticas educativas foi provocada, nos começos do século XX, como se sabe, pela chamada Educação Nova. Que, como também se tem dito, não trazia muito de novo, nem na prática nem na teoria. Pelo menos muitas das suas ideias básicas vamos encontrá-las em Rousseau, mais de um século antes, e algumas já em Montaigne (1533-1592), em Coménio (1592-1670) e em Fénelon (1651-1715), e muito mais para trás, e enquanto prática, em Sócrates.

Sem retirar a estes patronos essas ideias mestras, interessa realçar que há um conjunto de contributos inéditos que vão ganhando consistência científica durante o século XIX e XX, e que vão constituir uma poderosa alavanca da chamada Revolução da Pedagogia, tão radical que foi por alguns apelidada de copernicana. Não é ocasião para desenvolver esta área, mas não podemos ignorar os contributos da Psicologia, da Endocrinologia, da Biologia, bem como a perspetiva comportamentalista trazida pelo Behaviorismo, o avanço geral da medicina, os cuidados sanitários e higiénicos, etc. Ou seja, houve um novo espírito resultante da emergência científica das várias áreas, que foram proporcionando dados e conceitos que os educadores não puderam ignorar por muito tempo e que teriam que incorporar mais tarde ou mais cedo. Sobretudo os que tinham implicações educativas, os que se referiam às especificidades da infância e da adolescência, aos padrões de crescimento e de normalidade, aos estádios de desenvolvimento intelectual, etc. Acresce que a investigação educacional foi também ganhando autonomia e segurança metodológicas, revelando a educação 
como um fenómeno complexo, multidimensional, dependente de múltiplas variáveis, que é preciso analisar e conciliar para poder operacionalizar.

Mas, para além dos contributos científicos multidisciplinares e a necessidade de uma interdisciplinaridade na abordagem dos problemas educativos e, mais até, de uma transdisciplinaridade na investigação educacional, (Boavida \& Amado, 2006), havia outros fatores determinantes, aos quais nem sempre se dá atenção. As sociedades mais evoluídas dos finais do século XIX, em virtude da industrialização, por um lado, e da evolução sociocultural e política, resultante da democratização, por outro, necessitavam de indivíduos intelectualmente ativos e criativos, socialmente participantes, com competências para responder às novas necessidades de uma sociedade em rápida transformação.

7. Mas, para se obter este tipo de cidadão era necessária uma intervenção pedagógica que conseguisse conciliar um ensino de massas, ou para uma percentagem muito maior de pessoas, sem cair no ensino elementar, uniformizado e rígido que caracterizara a escola napoleónica. A qual, condicionada pelas circunstâncias em que se formara, estava preocupada sobretudo em alfabetizar massas que, repentinamente, tinham ganho outro estatuto social e político. O que a sociedade dos finais do século XIX pede à escola é diferente do que era solicitado nos finais do século XVIII. Ela agora necessita de indivíduos autónomos no pensamento e na ação, aprendendo conteúdos mais complexos e com novas competências sociais.

Estas necessidades implicam, a nível escolar, mudanças de objetivos, de estratégias e de metodologias, o que, por sua vez, obriga a uma relação pedagógica nova e a um estatuto e função diferentes, para o professor, para o aluno e para a própria escola (Boavida, 1982; Boavida e Barreira, 1986). Olhados à distância de cem anos, os "princípios da Educação Nova", (Planchard, 1982), hoje óbvios, quase inevitáveis, eram de facto a tradução de uma nova intenção para a escola e de uma consciência do que estava em jogo. Os homens da Educação Nova Dewey, Claparède, Ferrière, Decroly, Montessori, Adolfo Coelho, Magalhães Lima, Trindade Coelho, etc. - falam a partir de diferentes perspetivas pedagógicas, humanistas, médicas, filosóficas, etc. Mas, para lá destes aspetos de natureza pedagógica, são evidentes hoje 
as mudanças sociais e económicas que exigiam da escola uma formação diferente da que era dada até então.

8. Sendo assim, não parece que seja importante nem sensato perguntar, como às vezes se faz, se foram as teorias científicas e pedagógicas a comandar as mudanças na escola e, por sua vez, a transformar a sociedade, ou se foi esta que deu a intuição, aos mais atentos, das mudanças a fazer e os levou a meter mãos à obra. A realidade é constituída por muitos fatores em interação e a educação é um domínio onde estes se multiplicam e interagem, tornando o controlo difícil, ou mesmo impossível.

Todavia, se é certo que a educação está condicionada por contextos psicoafetivos e socioculturais, e por múltiplos factores que nem sempre controlamos, é bom não esquecer que ela é também uma força comandada por um dever ser, é um processo de transformação através do esforço e da vontade, e, portanto, é uma força de reação aos contextos, e um agente da sua transformação. A educação é, pois, simultaneamente, acção dependente dos contextos e agente de transformação desses contextos. É de presumir, porém, que os fatores socioculturais sejam determinantes, e assim o dever ser acaba por estar condicionado pelo contexto, na medida em que este influencia as metas, as interpretações e as formas de avaliação, quer estas reforcem os comportamentos quer os inibam.

Poderemos apresentar muitos exemplos da determinação sociocultural e económica na aceitação ou rejeição de práticas educativas, como muito bem notou Clausse (1976), mas reparemos nesta. Sendo Rousseau, como se costuma dizer, o pai espiritual das modernas pedagogias, nem sempre se terá reparado num pormenor revelador do condicionalismo a que essa influência esteve sujeita. O Emílio foi editado em 1762, e as primeiras "escolas novas" aparecem no fim do século XIX. A pioneira École des Roches surgiu, em França, em 1899 (Desmolins, 1909, Planchard, 1982), generalizando-se depois rapidamente este tipo de ensino. Isto é, as escolas com teoria e prática consideradas em linha com o pensamento pedagógico de Rousseau, expandiram-se na Europa quase cento e cinquenta anos depois da publicação do Emílio. O que é que isto significa? Que a pedagogia dita nova ou renovada se generalizou e ganhou aceitação geral quando a sociedade sentiu necessidade de novas competências para os cidadãos, 
e a mentalidade dominante, ou em ascensão por influência dos pedagogos mais modernos e influentes, já absorvera o essencial das suas ideias. E não quando uma obra isolada teorizou algumas ideias a que devia obedecer a educação, e que inclusive alguns pedagogos tinham já tentado pôr em prática, com duvidosos resultados e algum "nojo" social, como o caso de Pestalozzi, (1746-1827), por exemplo.

Isto é, a grande renovação pedagógica do nosso tempo dá-se quando a evolução sociopolítica, determinada pela democracia, e a evolução económica, potenciada pela industrialização, tornaram insuficiente um ensino ainda formatado para a alfabetização das massas, com uma informação rudimentar e a solicitação de um conjunto muito restrito de competências. As quais seriam suficientes para uma sociedade saída da Revolução Francesa e para o acesso de todos à cidadania, mas eram insuficientes para as necessidades sociais e económicas posteriores.

9. De facto, as referidas escolas propunham novidades que iam da conceção arquitetónica e do local de implantação, ao regime de internato; dos conteúdos ensinados, ao conceito de auto disciplina e de responsabilização dos alunos; das ideias de uma formação integral, às de uma educação para a transformação social; de uma educação estética e uma formação cívica, a uma educação manual e técnica, etc. (Claparède, 1973; Lourenço-Filho, 1963; Planchard, 1982). Daí a importância de criar, no aluno, a autonomia crítica, o sentido das responsabilidades e a capacidade inventiva. A necessidade que se fazia sentir destas competências resultava da profunda transformação do tecido económico-social. A educação integral, a partir da atividade do aluno, com o objetivo de criar um cidadão preparado para problemas complexos e inéditos, obrigou a ultrapassar o ensino livresco, ao nível médio, e desacreditou as memorizações sistemáticas do ensino elementar. E assim são desvalorizados a fixação e a reprodução, como as grandes tarefas escolares, e os conhecimentos estabelecidos, como o capital mais valioso, porque, de facto, não são já os mais necessários para a nova sociedade.

As necessidades novas implicam mudanças, como se referiu, não só ao nível das metodologias e das didáticas, mas também dos estatutos e das funções de alunos e professores, sendo, portanto de prever que os resultados sejam diferentes. Um aluno preparado para estudar e investigar com alguma autonomia ficará recetivo à inovação e 
à descoberta, valorizando a aprendizagem como um processo dinâmico e aberto. Ficará mais capaz de aceitar inovações, ao mesmo tempo que estará, em princípio, capaz de enfrentar os problemas e senti-los mesmo como desafios intelectuais. Mas, para isto, é necessária uma preparação específica, e que incida sobre as competências que se deseja desenvolver, problema menos fácil do que se possa julgar. Um outro, a quem se pede que memorize e reproduza, e que seja avaliado e valorizado por estas capacidades, ficará mais preparado em termos de conhecimentos, na medida em que os armazenou, mas terá dificuldade em analisar, diagnosticar e decidir, quando posto face a realidades inesperadas surgidas numa sociedade em acelerado processo de mudança. E, nestas condições, é provável que muitos dos conhecimentos armazenados não cheguem a ser utilizados, porque os conhecimentos necessários estão eles próprios em constante substituição.

10. Eu sei que algumas destas ideias estão gastas e que os problemas que hoje se colocam mais agudamente à educação em geral, e à escola em particular, serão já outros, ou têm novos elementos, ou são problemas resultantes das alterações introduzidas para solucionar os problemas que havia. Podemos pois pensar que o nó da questão já não está na dicotomia referida, mas resulta da tentativa de acertar a escola com os tempos mediante uma dinamização pedagógica. Isto é, hoje, provavelmente, alguns dos nossos problemas resultam da necessidade de, há cem anos, ter de alterar radicalmente os modos de ensinar, de fazer aprender e de avaliar, que eram então os dominantes. Ao tentar resolver certos problemas acabámos por criar outros, que são alguns dos atuais.

Mas isto não obriga a sair deste enquadramento interpretativo, porque sem ele será difícil compreender os problemas atuais mais pertinentes. O que parece interessante é analisar a dialética subjacente aos movimentos educativos, como condição de compreensão, e sermos capazes de evitar os desequilíbrios que estes movimentos implicam. O referido Clausse (1976), numa interpretação já clássica, chamou a atenção para o facto de que a oscilação histórica entre o formalismo e o realismo era acompanhada por uma oscilação entre estatismo e dinâmica social, tendo aquele (o formalismo) tendência para valorizar os conteúdos mais clássicos e abstratos, e os períodos de maior dinâmica social e económica exigirem conteúdos mais atuais e concretos. Algo 
de idêntico se pode dizer das metodologias. Umas estão mais presas aos conteúdos cognitivos e à necessidade de os reter e reproduzir, e com tendência para conservar; enquanto outras, pela sua dinâmica de procura, estão mais vocacionadas para as capacidades práticas, indispensáveis à resolução das situações problemáticas novas. Daqui resulta provavelmente uma certa desvalorização dos conhecimentos estabelecidos e uma valorização dos conhecimentos que a procura e a investigação vão proporcionando, menos fiáveis, é certo, mas gerados pelos problemas e acabando por constituir novas metodologias.

11. Mas quando se fala da oscilação entre tradição e renovação que percorre o século XX, e do sucesso ou insucesso desta renovação, temos que introduzir uma variável de natureza individual, a qual tem que ver com a formação, a interiorização e a capacidade dos professores de pôr em prática a modernidade pedagógica. Que influência tiveram os professores enquanto agentes desta transformação? Não foram só as ideias predominantes que se transmutaram do tradicional para o moderno, com toda a ambiguidade que os termos contêm, foi também o modo como estas ideias, e respetiva capacidade de aplicação, foram sendo vividas pelos agentes educativos, nas situações concretas, ou seja, a convicção e competência com que as práticas modernizantes foram concretizadas e o rigor com que foram avaliadas. A maioria dos educadores e professores dos ensinos básico, e sobretudo secundário, terá oscilado entre uma modernidade pedagógica, aparentemente com maus resultados, e portanto provocadora de insatisfaçãoe de insegurança, e os fantasmas de uma educação tradicional e de uma metodologia em conformidade, que transmitiam segurança. As quais se sente já não corresponderem às necessidades, nem estarem em linha com os tempos, nem serem já de fácil aceitação, mas pelas quais se sente forte atração, face ao aparente descalabro de que se ouve falar, e vê, ou julga ver. Há indícios de que, por vezes, a modernidade não passou das intenções, ou a sua aplicação foi esporádica, insegura, muitas vezes a contragosto, e logo substituída face aos primeiros resultados menos favoráveis. Daqui resulta uma situação que parece caracterizar o sentimento e a prática de muitos professores, ainda hoje: teoricamente modernos, ou a tender para isso, mas na prática tendencial ou até predominantemente clássicos.

É bom notar, no entanto, que esta oscilação de práticas educativas reflete as duas conceções tradicionais da educação. Os dois étimos 
(educare, ou alimentar, dar, fornecer, ensinar, e educere, fazer aparecer, fazer produzir) mostram bem que a educação sempre comportou estes dois movimentos (e correspondentes métodos) aparentemente opostos, e que poderemos identificar com as pedagogias clássica e moderna. O que significa que quer estejamos de um lado quer doutro não estamos em campos desconhecidos, mas apenas no desequilíbrio pontual resultante da predominância cíclica de uma destas vertentes, antitéticas e complementares. E que a componente dita mais moderna adquire toda a legitimidade no próprio conceito de educação, e que, portanto, não pode considerar-se uma "modernidade". Contudo, o trânsito de um modelo para outro tem sido vivido problematicamente por muitos, e é provavelmente neste processo que tem residido o problema que retirou convicção e segurança a muitos agentes educativos e eficácia ao próprio sistema.

Não é pois que haja algo de muito novo sobre a terra, em termos educativos, mas é evidente que à mudança a que todos nós fomos sujeitos nem sempre soubemos responder com a eficácia a que obrigavam as necessidades da realidade complexa e dinâmica a que tínhamos que fazer face. As transformações que a maioria dos sistemas educativos sofreu durante o século passado, pelas suas causas e pela problemática e conflitualidade da sua aplicação, terão provavelmente agravado um sentimento de crise institucional, acrescido pela confluência de factores sociais, políticos, espirituais e ideológicos a que chamamos de pós modernidade, para nos servir de algum consolo racional; mas que não nos permite superar os problemas, antes pelo contrário.

12. Uma problemática idêntica chegou em força ao ensino superior nos finais do século XX. Como já referimos, um dos maiores problemas das universidades, hoje, será o de harmonizar a democratização do acesso, com um ensino de qualidade, mantendo uma investigação em alto nível. De facto, a Universidade, como nunca antes em tal grau, tem que resolver uma difícil conciliação. Por um lado, ser cada vez mais um campo de investigação e estudo de todas as matérias, científicas ou em processo de cientificação ${ }^{1}$, por outro, solucionar a multiplicação incessante de

1 «Por isso a universidade, cuja vocação é intelectual, não pode excluir. Tem de incluir. A universidade tem de acolher, recolher, cultivar e transmitir tudo o que é actividade psíquica e espiritual humana. Racional, a-racional, i-racional, 
domínios de investigação. O que configura uma "universitas" muito mais complexa, e com um crescente potencial económico na aplicação dos conhecimentos, para o qual, durante séculos, não houve vocação nem necessidade, mas que agora somos obrigados a ter. Finalmente, manter estas exigências a alto nível e, simultaneamente, responder a uma demanda massiva por parte de uma população ávida de cultura e de promoção social. Ou seja, estamos confrontados com necessidades novas, e portanto sob a pressão de mudanças, não só pelas exigências postas por novos domínios de investigação e formação, como pelas implicações sociais e económicas, e com uma amplitude e intensidade inéditas. A Universidade está a ser submetida, com atraso de um século, a uma pressão idêntica à que sofreram os ensinos básico e secundário, mas mais agravada.

Cultivando um saber mais específico e aprofundado, com alunos adultos, e que constituíram, durante séculos, um grupo social restrito e selecionado, pôde conservar um ensino basicamente expositivo, e formas de avaliação segundo «o modelo napoleónico-latino», como diz Veiga Simão ${ }^{2}$. Mas as razões para esta menor preocupação pelas formas de ensino e de aprendizagem das matérias não era só de natureza psicoafetiva e etária. Para uma boa parte dos estudantes das universidades nem sempre havia adequação entre os estudos feitos e os cargos a ocupar na sociedade. Frequentemente a preparação adquirida era pouco relevante. Importante era o grau, era sobretudo uma nova forma de marcar a diferença social; era mais licença e justificação para certos cargos do que preparação académica específica e técnica indispensável à sociedade. A análise da nossa literatura do século

para-racional, trans-racional. Tem é de o fazer com a profundidade e altitude que são o selo identitário do intelecto. A obrigação íntima, solene do intelecto é procurar, encontrar e dar a Verdade. A universidade surgiu, no início do segundo milénio da era cristã, para cultivar a verdade de forma absoluta, sem equívocos, sem compromissos espúrios» (Patrício, 2008, 70).

${ }^{2}$ Modelo que, segundo Veiga Simão $(2001,105)$, herdou «o centralismo estatal e a falta de preocupação com o elevado insucesso escolar, tido não só como normal mas, também, como "não responsabilizante" para as instituições. Para sossegar as consciências, a responsabilidade do insucesso é exclusivamente colocada na articulação entre níveis de ensino, como no caso do acesso universitário». 
XIX, tal como a de outros países, mostra como um curso dá para um "lugar" na Administração Pública, mas com funções nem sempre com relevância económica, e até frequentemente dispensáveis.

Ora, são estas condições que estão em mudança em virtude da ordem económica globalizada e da competição internacional. A Europa deixou de ser o centro do mundo, e em virtude da nova situação não estamos em condições de continuar a manter estas formas de aprendizagem e estes graus de desperdício. As novas condições exigem outras competências para lá das tradicionais e outro nível de eficácia e de rentabilidade no sistema. O facto de não haver, até há pouco, concorrência científica e tecnológica fora da Europa e dos Estados Unidos, e de internamente as massas andarem arredadas da formação universitária, criou, durante séculos, uma muralha protetora a uma classe e numa parte do Mundo. Mas isso chegou ao fim. Esta enorme vantagem, para além das injustiças em que assentava, não obrigava, como hoje, as universidades a preocuparem-se muito com os métodos necessários a uma preparação inserida na dinâmica socioeconómica, nem com os níveis de perda dos seus alunos.

É óbvio que o ensino superior terá que passar a formar para essa realidade nova. E já o está a fazer, uma vez que ele é cada vez mais uma poderosa locomotiva das áreas científicas e técnicas - e portanto económicas. Temos assistido a um enorme desenvolvimento tecnológico e a uma multiplicação dos seus campos de aplicação. E não pára de crescer a dependência da investigação universitária relativamente à indústria, e a valorização das componentes práticas e experimentais do conhecimento. E isto está a manifestar-se também nas ciências sociais e nas humanidades, na cultura em geral, onde se começa a ganhar consciência das potencialidades económicas desses domínios.

De qualquer modo o processo de transformação está em marcha e é preciso encontrar uma solução para ele. Por outro lado, ao longo da sua história, a Universidade sempre se foi adaptando às novas condições que a sociedade e o espírito científico, em evolução, lhe iam determinando; e isto pela própria evolução do corpo científico e cultural onde ela tem sido, desde a sua origem, força determinante. A sua capacidade de adaptação às novas conceções de ciência e de investigação científica, ao longo dos séculos XVII e XVIII, onde as mudanças exigidas foram muito mais profundas que as actuais, confirmam o facto, como tentámos demonstrar noutro trabalho (Boavida, 2010). 
13. A recente preocupação das universidades com as muitas possibilidades dadas pelas modernas pedagogias torna-se assim compreensível. A necessidade de pôr os alunos a participar mais na sua preparação, a diversificar as formas de a obter, a adquirir competências de investigação, individual e em equipa, em suma, a criação de novos hábitos de trabalho (Veiga Simão et al. 2008; Baudrit, 2009; Frison \& Veiga Simão, 2009; Mundina, 2009) tornou-se uma necessidade. Mas para a qual temos que garantir padrões de qualidade. Face à nova situação torna-se indispensável desenvolver e diversificar competências, e tendo-se tornado valores preciosos a autonomia de pensamento, a criatividade e a capacidade de decisão (Bahia, 2008, Câmara, 2009) teremos que ir à procura dos meios de formar cidadãos com estas características. O que traz novos problemas, certamente, porque a Universidade não pode permitir que investigação e ensino se desenquadrem e desarticulem. Mas a situação é esta e a investigação pode vitalizar e produzir uma contínua e coerente renovação do que se ensina e aprende. Só assim os alunos poderão obter formação em consonância com o que necessitam hoje a sociedade, a economia e a cultura.

É portanto um problema científico, porque o que todos tememos é que esta situação venha a produzir degradação no ensino e na cultura universitários. Mas também é político, porque a possibilidade de investigar passa pelas condições de trabalho, pelos recursos qualificados postos à sua disposição, pelos fundos a que as universidades e centros de investigação terão ou não acesso, etc. Mas é também pedagógico, porque a possibilidade de articular a investigação com a aprendizagem e com a divulgação está nas estratégias de investigação, de ensino, de aprendizagem e de avaliação que, em conjunto, forem adotadas (Boavida et al., 2006; Silva, 2008). E isto é, em última análise, pedagógico, porque o segredo não está em tirar conteúdos à formação científica para dar à pedagógica, nem em apresentar as matérias de uma maneira leve e atraente, como por vezes se pensa, mas em tornar estas duas componentes articuladas e funcionais. A solução não está numa soma ou diminuição mas numa multiplicação dinamizadora.

Tradicionalmente os professores transmitiam os conhecimentos, ou o resultado das investigações próprias ou alheias, partindo do princípio de que o conteúdo científico vale por si e é independente dos métodos do transmitir e fazer aprender. Ora, é esse paralelismo que 
está em causa, e é a este nível que as mais importantes mudanças terão que se dar. A competência científica não resolve automaticamente os problemas pedagógicos, nem o pedagógico é um dourar das coisas, mas um catalizador, um fator de funcionalidade do científico e através dele. E, sendo assim, a necessidade de mudança que a sociedade está a impor à Universidade pode vir a ser a condição de um importante redimensionamento cultural e científico. Sei que isto é problemático, e até polémico, mas quase sempre o segredo da eficácia está no modo e não na quantidade. $\mathrm{O}$ grande desafio actual está na capacidade em resolver, sem perda, esta mudança inevitável.

14. Alguns factos históricos são importantes para perceber que, desde cedo, a Universidade Portuguesa não desprezou os problemas pedagógicos em geral, e a formação dos professores em particular. E que se preocupou em fazer investigação científica neste domínio, acompanhando a investigação psicológica e psicopedagógica que nascia e se afirmava nos centros universitários mais avançados. E que, portanto, esta revolução pedagógica, que as condições agora exigem, não nos apanha desprevenidos, no sentido de que houve investigadores, instituições e publicações que atestam a preocupação da Universidade de Coimbra por estas questões, ao longo do século XX. Que talvez pudessem ter tido mais desenvolvimento e com maior continuidade, mas foi assim talvez porque as condições socioculturais e económicas, ainda o não estavam a exigir tanto como hoje.

Entre os exemplos mais significativos refiro alguns, como a criação das Escolas Normais Superiores, em Coimbra e em Lisboa, a criação do $1^{\circ}$ Laboratório de Psicologia Experimental de Portugal, na Universidade de Coimbra, e a fundação da Revista Portuguesa de Pedagogia.

A Escola Normal Superior da Universidade de Coimbra (tal como a de Lisboa) foi fundada em 1911, faz portanto agora cem anos, tendo, contudo, só começado a lecionar no ano letivo de 1915/16. Mas dava continuidade ao anterior Curso de Habilitação para o Magistério Secundário, que funcionava desde o começo do século. Entre 1927 e 1930 esta Escola publicou o Arquivo Pedagógico, onde, segundo Gomes $(1988,4)$, «predominam os artigos sobre metodologia do ensino e sobre instituições educativas de outros países». Refira-se que este curso era constituído por quatro anos, sendo os três primeiros 
de formação científica e o $4^{\circ}$ de preparação pedagógica, isto é, «...especial aplicação e exercitação para o magistério secundário», com as seguintes disciplinas: Psicologia e Lógica, Pedagogia do Ensino Secundário, História da pedagogia e em especial da metodologia do ensino secundário a partir do século XVI em diante, e provas de avaliação de conhecimentos, uma aula presencial e uma tese.

As Escolas Normais Superiores, anexas às universidades, tinham por objetivo «promover a alta cultura pedagógica e habilitar para o magistério dos liceus, das escolas primárias (...) e para admissão ao concurso para os lugares de inspectores do ensino». O que indicia que a preocupação de formação científica dos professores não foi só preocupação de alguns universitários, mas era um objetivo prioritário da $1^{\text {a }}$ República. As suas disciplinas abarcam um largo âmbito, o que revela também, por parte dos legisladores e dos especialistas envolvidos, informação e preocupação por uma formação pedagógica dos professores, alargada e sólida: Psicologia infantil, Moral e instrução cívica superior, Teoria da Ciência, Higiene geral e, em especial, higiene escolar, Metodologia geral das Ciências do Espírito, Organização e legislação comparada do Ensino Secundário, Organização e legislação comparada do Ensino Primário, Metodologia geral das Ciências Matemáticas.

Em 1930, em plena ditadura salazarista, foram extintas as Escolas Normais Superiores e substituídas pela criação, nas Faculdades de Letras de Coimbra e de Lisboa, das Secções de Ciências Pedagógicas.

Um outro exemplo significativo foi a fundação do $1^{\circ}$ Laboratório de Psicologia Experimental, na Universidade de Coimbra, em 1912, no âmbito da reforma do ensino universitário, empreendida pelo $1^{\mathrm{o}}$ Governo Provisório da $1^{\mathrm{a}}$ República. Este laboratório ficava anexo à recém fundada Faculdade de Letras e fora criado, segundo o próprio diploma legal, para ser «auxiliar indispensável dos estudos filosóficos e dos estudos pedagógicos da Escola Normal Superior». É de elementar justiça referir o nome de Alves dos Santos, verdadeiro pioneiro dos estudos de psicofísica em Portugal, e a quem se deve em grande parte a criação do laboratório. É justo não esquecer também o apoio que a comunidade universitária deu ao projeto, subsidiando a Universidade diversas visitas de Alves dos Santos, ao Laboratório de Psicologia Fisiológica de Paris e ao Laboratório de Psicologia da Universidade de 
Genebra, onde Alves dos Santos estagiou com Claparède, bem como a compra dos aparelhos de alta precisão que as experiências requeriam.

Apesar da crise já a anunciar-se na psicofísica, com os primeiros trabalhos de Wertheimer, para a teoria gestaltista, e de estar prestes a surgir a «revolução» comportamentalista da psicologia, com o manifesto behaviorista de John Watson (1913), pondo em causa a psicologia "elementarista", e criando uma tendência predominante durante anos, a ideia de que as questões psicológicas e pedagógicas deviam ser, sempre que possível, baseadas em investigação científica, tem na criação do Laboratório e nos seus trabalhos, uma prova insofismável. Acresce que este processo renovador foi apoiado por legislação moderna e atenta, e que só as condições políticas adversas impediram maior concretização e continuidade.

Outro facto também muito significativo foi a fundação, por Émile Planchard, em 1961, da Revista Portuguesa de Pedagogia. Suspenso há muito o projeto do Arquivo Pedagógico, com a extinção da Escola Normal Superior, ela traduziu a preocupação da Universidade, mais explicitamente de alguns professores da Faculdade de Letras da Universidade de Coimbra, pela necessidade de dar publicidade aos estudos e investigações que se faziam neste âmbito, e sobretudo de vir a ser um veículo de informação e difusão das teorias e das práticas pedagógicas. Em boa hora o fizeram os seus fundadores. A Revista Portuguesa de Pedagogia, com uma pequena interrupção, continua a publicar-se regularmente, tendo-se vindo a modernizar e internacionalizar progressivamente. Nas suas páginas têm publicado trabalhos grandes nomes, nacionais e internacionais, e o seu espólio pedagógico e psicológico deverá ser motivo de orgulho para todos nós.

Finalmente, não podemos deixar de referir a criação do Curso Superior de Psicologia, na Universidade de Coimbra, em 1977, por iniciativa de um grupo de professores da Faculdade de Letras, e no âmbito desta Faculdade, e a sua evolução para a atual Faculdade de Psicologia e de Ciências da Educação, em 1980. Factos que corresponderam à necessidade de autonomização de um domínio científico em plena expansão e às solicitações de uma sociedade em processo de diversificação cultural e económica. O que parece confirmar o essencial do que se pretendeu dizer neste artigo. 


\section{Bibliografia}

Abreu, M. V.; Oliveira, A. M. (1999). O Laboratório de Psicologia Experimental da Universidade de Coimbra. Coimbra: Faculdade de Psicologia e de Ciências da Educação.

Bahia, S. (2008). Criatividade e universidade entrecruzam-se? Sísifo Revista de Ciências da Educação, 7, 51-62.

Boavida, J. (1982). Métodos pedagógicos "tradicionais": esboço de uma reformulação crítica. Revista Portuguesa de Pedagogia, XVI, 205-226.

Boavida, J.; Barreira, C. (1986). Contributos para a compreensão dos modelos, clássico e moderno da relação pedagógica. Revista Portuguesa de Pedagogia, XX, 337-344.

Boavida, J. Barreira, C. e Araújo, N. (2006). Avaliação formativa - novas formas de ensinar e aprender. Revista Portuguesa de Pedagogia, XL, 3, 95-133.

Boavida, J.; Amado, J. (2006). Ciências da Educação - Epistemologia, identidade e perspectivas. Coimbra: Imprensa da Universidade de Coimbra.

Boavida, J. (2010). Ensino superior para o novo século: problema ou solução? Revista Portuguesa de Pedagogia, XLIV, 1, 9-36.

Baudrit, A. (2009). A tutoria em diferentes domínios. In Veiga Simão, M.; Caetano, A. P.; Freire, I. Tutoria e mediação em educação. Lisboa: Educa, 11-22.

Câmara, A. (2009). O futuro inventa-se - a formação de cidadãos criativos e empreendedores e o papel da nova universidade. Lisboa: Objectiva.

Claparède, E. (1973). L'Education fonctionnelle. Neuchâtel: Delachaux et Niestlé.

Clausse, A. (1976). A relatividade educativa - esboço de uma história e de uma filosofia da escola. Coimbra: Almedina.

Demolins, E. (1909). L'éducation Nouvelle - L'École des Roches. Paris: Librairie de Paris.

Frison, L. M.; Veiga Simão, M. (2009). Acção tutorial em contexto de trabalho e auto-regulação da aprendizagem. In Veiga Simão, A. M.; Caetano, A. P.; Freire, I. Tutoria e mediação em educação. Lisboa: Educa, 23-48.

Fullat, O. (1983). Filosofías de la educación. Barcelona: CEAC. 
Gomes, J. F. (1988). Situação actual da História da Educação em Portugal. Revista Portuguesa de Pedagogia, 3-38.

Gomes, J. F. (1989). A Escola Normal Superior da Universidade de Coimbra (1911- 1930). Lisboa: Instituto de Inovação Educacional.

Lourenço-Filho, M. B. (1963). Introdução ao estudo da Escola Nova. São Paulo: Edições Melhoramentos.

Mundina, J., B. (2009). Proyetos y programas de tutoría de educación superior. Enfoque personalisado de la tutoría. In Veiga Simão, M. ; Caetano, A. P.; Freire, I. Tutoria e mediação em educação. Lisboa: Educa, 49-66.

Patrício, M. F. (2008). A missão da universidade. In C. Reimão (coord.). Pedagogia universitária - práticas e processos em tempo de mudança. Lisboa: Universidade Lusíada Editora, 69-83.

Planchard, E. (1982). A Pedagogia contemporânea. Coimbra: Coimbra Editora.

Silva, A. J. (2008). Uma pedagogia para a responsabilidade e para o sucesso - sua ponderação num sistema de avaliação do Ensino Superior. In C. Reimão (coord.). Pedagogia universitária - práticas e processos em tempo de mudança. Lisboa: Universidade Lusíada Editora, 37-41.

Veiga Simão, J. (2001). À procura da qualidade e da excelência no ensino superior. In C. Reimão (org.). A formação pedagógica dos professores do ensino superior. Lisboa: Colibri, 105-109.

Veiga Simão, A. M.; Flores, M. A.; Fernandes, S.; Figueira, C. (2008). Tutoria no ensino superior. Sísifo - Revista de Ciências da Educação, 7, 75-88. 